\title{
A Two-Phase Resistance Response of Venturia inaequalis Populations to the QoI Fungicides Kresoxim-Methyl and Trifloxystrobin
}

\author{
Wolfram Köller, D. M. Parker, W. W. Turechek, and Cruz Avila-Adame, Department of Plant Pathology, Cornell \\ University, New York State Agricultural Experiment Station, Geneva, NY 14456; and Keith Cronshaw, BASF Akti- \\ engesellschaft, Agricultural Centre, 67114 Limburgerhof, Germany
}

\begin{abstract}
Köller, W., Parker, D. M., Turechek, W. W., Avila-Adame, C., and Cronshaw, K. 2004. A twophase resistance response of Venturia inaequalis populations to the QoI fungicides kresoximmethyl and trifloxystrobin. Plant Dis. 88:537-544.

The class of fungicides acting as respiration inhibitors by binding to the Qo center of cytochrome $b$ (QoIs) are in wide use for the management of apple scab caused by Venturia inaequalis. In order to assess responses of V. inaequalis populations to treatments with QoIs, sensitivities of isolates were determined for germinating conidia or for mycelial colonies developing from germinating conidia. Under both test conditions, inhibitory potencies of kresoxim-methyl and trifloxystrobin were largely equivalent. V. inaequalis populations treated with QoIs in a commercial and an experimental orchard both responded with significant shifts toward declining QoI sensitivities. However, the population responses were quantitative in nature, and highly resistant isolates indicative of a cytochrome $b$ target site mutation were not detected. $V$. inaequalis populations from both orchards investigated also were fully resistant to sterol demethylation-inhibiting fungicides (DMIs) such as fenarimol and myclobutanil, but isolate sensitivities to QoIs and DMIs were largely unrelated. Performance tests with kresoxim-methyl and trifloxystrobin at the experimental orchard diagnosed as DMI-resistant revealed that the quantitative shift toward declining QoI sensitivities did not constitute the status of practical QoI resistance. In contrast to these quantitative responses, emergence of qualitative QoI resistance was documented for $V$. inaequalis in an orchard in North Germany, which had been treated intensively with a total of $25 \mathrm{QoI}$ applications over four consecutive seasons. Isolates retrieved from the orchard were highly resistant to both kresoxim-methyl and trifloxystrobin and were characterized as G143A cytochrome $b$ mutants. The results indicated that the paths of QoI resistance can be both quantitative and qualitative in nature. A similar phenomenon has not been described before. Circumstantial evidence suggests that the quantitative phase of $V$. inaequalis population responses to QoIs might be succeeded by a quantitative selection of highly resistant G143A target-site mutants.
\end{abstract}

The paths of development of resistance to fungicides have been divided into quantitative or qualitative population responses $(7,16,19)$. In general, quantitative responses are mediated by the presence of multiple genes, each contributing a relatively small factor of resistance. If genotypes equipped with an elevated number of such resistance genes escape full control at a given application rate of a given fungicide, they will gain in competitiveness and will be selected toward increasingly higher

Corresponding author: W. Köller

E-mail:WK11@cornell.edu

Present address of C. Avila-Adame: Department of Plant Pathology, North Carolina State University, Raleigh 27695.

This work was supported, in part, by BASF Corporation, Research Triangle Park, NC; Bayer CropScience, Research Triangle Park, NC; and the New York Apple Research and Development Program.

Accepted for publication 8 January 2004.

Publication no. D-2004-0304-01R

(C) 2004 The American Phytopathological Society frequencies. As documented for Venturia inaequalis and the sterol demethylationinhibiting fungicides (DMIs), however, the level of control achieved for isolates distinguished by an elevated number of combined resistance genes remains dose dependent (22).

In contrast, a single resistance gene conferring a very high level of resistance to a particular fungicide will not allow disease control at any feasible dose of that fungicide. Complete lack of control will lead to the rapid selection of highly resistant subpopulations, thereby manifesting a qualitative population response $(7,16,19)$. The cause for such qualitative responses is, most often, a mutational change of the target site annulling inhibitor binding to the respective target site $(7,16,19)$.

Fungicides acting as respiration inhibitors by binding to the Qo center of cytochrome $b$ (QoIs), which were derived from the class of antifungal strobilurins, constitute a modern class of broad-spectrum fungicides $(6,33,37,43)$. Several strobilurin-resistant target site mutants of Saccharomyces cerevisiae $(8,21,44,45)$ were described prior to the introduction of com- mercial QoIs, indicating that problems with qualitative QoI resistance might emerge. Consequently, risk assessment studies with $V$. inaequalis as one of the QoI target pathogens were initiated before kresoxim-methyl and trifloxystrobin were introduced in the United States (2931,44,45).

During our risk assessment studies, it was noticed that the effect of alternative respiration as a natural mechanism of QoI resistance $(1-3,13,42)$ could be detected readily in in vitro tests evaluating sensitivities of $V$. inaequalis isolates (29-31). However, it also was apparent that this resistance mechanism had negligible impact on the performance of kresoximmethyl in the protection of apple leaves from apple scab $(29,31)$. A baseline study of $V$. inaequalis populations revealed that kresoxim-methyl sensitivities of germinating conidia were separated by a factor of 60 (29). This relatively broad range of isolate sensitivities, however, was only partly explained by the rescue mechanism inherent in alternative respiration (30), indicating that other mechanisms such as accelerated detoxification of QoIs (42) were involved as other determinants of isolate sensitivities. Consequently, a potential for quantitative resistance responses similar to the DMIs $(20,24)$ and dodine (25) was predicted for the QoIs (30).

The sample size employed in our QoI baseline study allowed us to predict that $98 \%$ of baseline isolates will fall into the range of the baseline sensitivities determined $(29,30)$. The sample size limitation implied, however, that approximately $2 \%$ of baseline isolates could fall outside this sensitivity range (28). This possibility was addressed in laboratory mutation studies, which allowed us to identify a highly QoIresistant $V$. inaequalis mutant distinguished by a G143A amino acid exchange in the cytochrome $b$ target site $(21,31,45)$. The G143A mutation, which signaled a potentially high risk of qualitative QoI resistance responses, has since been affiliated with the occasionally rapid emergence of practical QoI resistance documented for several other pathogens associated with important diseases $(5,6,10,11)$.

Kresoxim-methyl has been in use in Europe for the management of scab in commercial orchards since 1996 and in experimental orchards since 1990 (27). Testing QoI sensitivities of $V$. inaequalis 
populations in 1995 and 1996 suggested that up to 54 kresoxim-methyl applications over several seasons had no measurable effect on kresoxim-methyl sensitivities in experimental orchards, a result interpreted as indication for a low risk of QoI resistance (27). In this study, we quantified the initial responses of $V$. inaequalis populations to QoIs for a commercial and an experimental orchard in the United States, where QoIs were introduced commercially in 1999. Respective sensitivity changes were compared with the QoI sensitivities of highly resistant isolates of $V$. inaequalis collected from a commercial apple orchard in North Germany after QoI fungicides had been used intensively for 4 years.

\section{MATERIALS AND METHODS}

Materials. Fenarimol, kresoxim-methyl, myclobutanil, and trifloxystrobin were obtained from their respective manufacturers as technical products. Potatodextrose agar (PDA) and potato-dextrose broth (PDB) was purchased from Difco Laboratories (Detroit). Disposable petri dishes (100 by $15 \mathrm{~mm}$ ) were from Fisher Scientific (Pittsburgh). All other chemicals were from Sigma Chemical Company (St. Louis), if not specified otherwise.

Origin of $\boldsymbol{V}$. inaequalis population. The populations described here originated from four different sampling sites:

Commercial orchard in Michigan. Primary scab had been managed for over 10 years with DMI-mancozeb mixtures until a control failure was observed in 1999. Scab management in 2000 and in 2001 included four applications of QoI fungicides per season, when abundant scab symptoms were observed in June 2001 after QoI applications were made. Approximately 60 diseased leaves were collected from several trees across the orchard, and individual isolates were grown from single conidia originating from different lesions (24).

Commercial orchard in Germany. Scab management programs at the orchard located in North Germany involved 25 QoI applications in total: 6 in 1997, 9 in 1998, 6 in 1999, and 4 in 2000. Abundant scab symptoms were noticed in June 2000 following the four treatments with QoIs. Approximately 40 diseased leaves were sampled in June 2001 from several trees in a block treated with two applications of the protective fungicide dithianon.

Experimental orchard in New York. The experimental orchard consisted of a block of 27-year-old 'Cortland' trees planted on MM.106 rootstock. At this site, the performance of various fungicides on apple scab and powdery mildew has been tested for over 20 years, with first trials involving QoI fungicides conducted in 1994. Approximately 60 diseased leaves were sampled in June 2002 from eight control trees not treated with fungicides for the entire season. Suspensions of conidia were pre- pared from individual lesions, and isolates were grown from single conidia of the respective suspensions.

Backyard apple trees in Pennsylvania. The approximately 80-year-old apple trees were located in a private backyard remote from commercial apple orchards. The trees had not been managed for $>20$ years and were, most likely, never treated with fungicides. Approximately 60 diseased leaves were collected in June 2002, and conidia were dispersed from single lesions. Isolates were obtained from germinating conidia originating from separate lesions.

Tests of fungicide sensitivities. $D M I$ sensitivities. Sensitivities of $V$. inaequalis to DMIs were determined for all three populations according to a procedure described previously (24). In brief, relative growth of mycelia (RGm) was determined at discriminatory doses of fenarimol at $0.05 \mu \mathrm{g} \mathrm{ml}^{-1}$ and myclobutanil at $0.1 \mu \mathrm{g}$ $\mathrm{ml}^{-1}$ after 6 weeks of mycelial colony growth on PDA at $20^{\circ} \mathrm{C}$. RGm values are defined as colony diameters (treated with DMIs)/colony diameters (nontreated) $\times$ 100. Isolates displaying $\mathrm{RGm}$ values $>80$ were classified as DMI-resistant, as defined by Köller et al. (24).

QoI sensitivities of germinating conidia. Sensitivity tests were conducted with conidia prepared from individual isolates of $V$. inaequalis retrieved in 2001 from the Michigan orchard. Details of the test procedure have been described previously $(29,30)$. In brief, conidia were prepared from mycelia (32) and relative germination (RGg) (percentage of germination [treated with QoIs]/percentage of germination (nontreated) $\times 100$ ) was determined at two discriminatory doses of kresoxim-methyl: 0.01 and $0.1 \mu \mathrm{g} \mathrm{ml}^{-1}$ plus salicylhydroxamic acid (SHAM) at $100 \mu \mathrm{g} \mathrm{ml}{ }^{-1}$. Although the low QoI dose allowed quantification of isolate sensitivities (29), the mixture with SHAM was fully inhibitory to all baseline isolates tested previously (30) but failed to inhibit conidia germination for a QoI-resistant laboratory mutant (45).

The same conidia germination test was employed for determining 50\% effective dose $\left(\mathrm{ED}_{50}\right)$ values of 16 typical baseline isolates described previously (29) and maintained in our culture collection. Here, concentrations of kresoxim-methyl and trifloxystrobin were $0.0001,0.001,0.01$, 0.1 , and $1 \mu \mathrm{g} \mathrm{ml}^{-1}$. Respective tests were done in the absence or presence of SHAM $\left(100 \mu \mathrm{g} \mathrm{ml}^{-1}\right) . \mathrm{ED}_{50}$ values were determined by log-linear regression of $\mathrm{RGg}$ values and QoI concentrations.

QoI sensitivities of developing colonies. The procedure for measuring QoI sensitivities of germinating conidia necessitated their production from mycelia of individual isolates $(29,30)$. This test was simplified by directly measuring sensitivities of clonal conidia produced in individual scab lesions. For the modified test, distinct round lesions were cut from approximately 60 leaves with a cork borer $(0.8 \mathrm{~cm}$ in diameter). Diseased leaves were collected from the backyard apple trees in Pennsylvania and the experimental orchard in New York. Leaf discs were placed into open Eppendorf tubes and stored for up to 3 months at room temperature. Prior to sensitivity tests, the Eppendorf tubes were filled with $1 \mathrm{ml}$ of water, conidia were suspended by shaking, and the leaf discs were removed. Individual lesions contained 30,000 to 100,000 conidia.

Suspensions of conidia (100 $\mu \mathrm{l}$ per petri dish) were spread over the surface of PDA amended with antibiotics as described previously (24). For nontreated control samples, conidial suspensions were diluted 1:10. For QoI sensitivity tests, conidial suspensions were used directly. PDA was amended with kresoxim-methyl or trifloxystrobin to yield discriminatory doses of $0.02 \mu \mathrm{g} \mathrm{ml}^{-1}$ when used alone and of 0.2 $\mu \mathrm{g} \mathrm{ml}^{-1}$ when used in mixture with SHAM at $100 \mu \mathrm{g} \mathrm{ml}^{-1}$. Prior to the amendment of PDA, the QoIs were dissolved in acetone and SHAM in 1:1 (vol/vol) acetone:methanol. The final solvent concentrations of $0.1 \%$ had no effect on conidia germination and colony formation.

Petri dishes sealed with parafilm were incubated for 7 days at $20^{\circ} \mathrm{C}$. The sizes of colonies formed from conidia germinating on PDA or PDA amended with QoIs at a dose of $0.02 \mu \mathrm{g} \mathrm{ml}^{-1}$ were measured by projecting colonies on the screen of a monitor (Trinitron PVM-1343MD; Sony Corp., San Jose, CA), employing a video camera (EIS RJ500; Empire Imaging Systems, Inc., North Syracuse, NY) connected to a macro lens (Macro-JE, $50 \mathrm{~mm}, \mathrm{~F} 2.8$; Sigma, Tokyo). Sizes of five magnified mycelial colonies per petri dish were measured at the points of their largest expansion. RGm values were defined as mean colony sizes (treated with fungicide)/mean colony sizes (nontreated) $\times$ 100. Treatments containing QoIs at $0.2 \mu \mathrm{g}$ $\mathrm{ml}^{-1}$ plus SHAM were assessed qualitatively by evaluating the emergence of $V$. inaequalis colonies after 2 weeks of incubation.

Fungal contaminants were present in all samples tested. However, contaminant-free surface regions allowed evaluation of sufficient numbers of $V$. inaequalis colonies in $>80 \%$ of the isolate samples tested. Antibiosis caused by fungal contaminants was never observed.

QoI sensitivity tests on apple leaves. The kresoxim-methyl sensitivity of a mixed conidia population derived from diseased leaves from an orchard in North Germany was tested in vivo using methods similar to a procedure described by Olaya and Köller (29). Conidia suspended from approximately 40 diseased leaves first were propagated on nontreated apple seedlings. Apple seedlings were sprayed $24 \mathrm{~h}$ prior to inoculation with kresoxim-methyl at 500 
$\mu \mathrm{g} \mathrm{ml}^{-1}$. Leaves were infected with a mixture of conidia suspended from diseased leaves of seedlings, and disease symptoms were rated 14 days after inoculation.

Fungicide performance. Performance tests were conducted in 2002 in a block of 37-year-old 'Cortland' trees at the experimental orchard in New York. Single-tree plots were arranged in a randomized complete block design, with four replicate plots for each treatment and four replicate nontreated control trees. Mancozeb (Dithane RSNT 75DF; 3,300 g/ha) was applied three times to all trees receiving fungicide treatments, on 18 April (tight cluster), 1 May (extended pink), and 15 May (late bloom/early petal fall). The fungicides to be tested were applied on 24 April (pink), 8 May (bloom), 21 May (petal fall), and 29 May (first cover). They were mancozeb (Dithane RSNT 75DF; $3.300 \mathrm{~g} / \mathrm{ha}$ ), myclobutanil (Nova 40WP; $315 \mathrm{~g} / \mathrm{ha}$ ) in mixture with mancozeb (Dithane RSNT 75DF; 3.300 g/ha), kresoxim-methyl (Sovran 50WG; 280 or $440 \mathrm{~g} / \mathrm{ha}$ ), and trifloxystrobin (Flint $50 \mathrm{WG} ; 140$ or $210 \mathrm{~g} / \mathrm{ha}$ ). All fungicide doses rates adhered to the application rates recommended in the United States.

Mancozeb as the first treatment was applied to all fungicide blocks 5 days after the first potential infection period was recorded. All other fungicide applications were made one to six days prior to infection periods and, thus, reflected a largely protective spray schedule. Additional fungicide treatments consisting of thiophanate-methyl (Topsin M 70WSP; 180 $\mathrm{g} / \mathrm{ha}$ ) mixed with captan (Captan 50W; $1,700 \mathrm{~g} / \mathrm{ha}$ ) were applied on 7 and 20 June 7, 18 July, and 1 August to all treated blocks. All fungicides were applied to runoff with a handgun at 350 psi. Application rates of the various fungi-

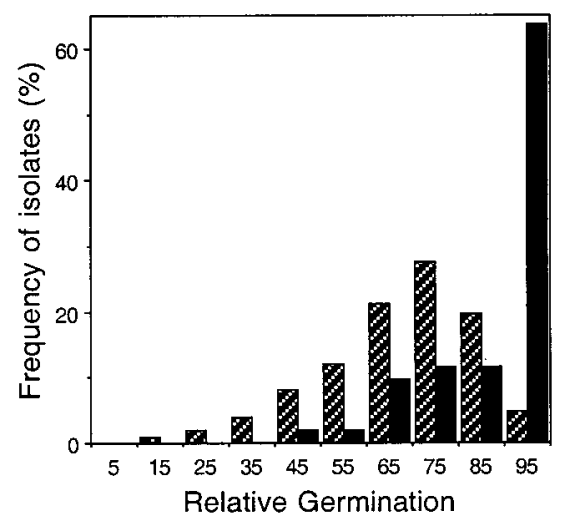

Fig. 1. Frequency distributions of Venturia inaequalis isolate sensitivities to kresoximmethyl based on relative germination of conidia. Sensitivities of germinating conidia were tested with kresoxim-methyl at $0.01 \mu \mathrm{g} \mathrm{ml}^{-1}$. Hatched bars designate the distribution of 250 baseline isolates described previously (29). Closed bars reflect the sensitivity distribution of $V$. inaequalis isolates from an orchard in Michigan sampled in $2001(n=52)$. cides were calculated for a spray volume of 2,800 liters/ha.

Ascospore release was monitored with a Burkhard spore trap from 15 April through 25 May. Six major release events were recorded, with hours of leaf wetness, the average temperature, and the accumulative percentage of ascospores released given in parentheses: $29-30$ April $\left(20 \mathrm{~h}, 4^{\circ} \mathrm{C}\right.$, $22.5 \%), 2$ May $\left(7 \mathrm{~h}, 8^{\circ} \mathrm{C}, 40.3 \%\right), 7$ May $\left(5 \mathrm{~h}, 14^{\circ} \mathrm{C}, 47.2 \%\right), 9$ May $\left(4 \mathrm{~h}, 11^{\circ} \mathrm{C}\right.$, $59.7 \%), 12-14$ May $\left(56 \mathrm{~h}, 13^{\circ} \mathrm{C}, 91 \%\right)$, and $16-18$ May $\left(18 \mathrm{~h}, 7^{\circ} \mathrm{C}, 99.5 \%\right)$. The first likely infection period on 13 April at the green-tip stage occurred prior to the start of monitoring ascospore release.

Disease incidences were determined on 16 August. For fruit scab, 100 apples per tree were examined for the presence or absence of at least one scab lesion. For leaf scab, the absence or presence of at least one scab lesion was recorded for the first 10 fully expanded leaves on 10 terminal branches per tree.

Characterization of cytochrome $b$. Sequences of cytochrome $b$ were analyzed according to the procedures described in previous studies $(1,5,31,43,44)$. Mycelia for extraction of RNA were prepared in liquid PDB for isolates derived from the orchard in Michigan, and on PDA for isolates originating from the orchard in Germany. RNA was extracted employing the Tri Reagent-RNA/DNA/Protein isolation system (Molecular Research Center, Inc., Moonachie, NJ) according to the manufacturer's protocol. The two homologous primers 5'-GTCATCCACTATTGAGATTAG-3' and 5'-CTGCAAACATAGCTATAACAC- $3^{\prime}$ used in reverse-transcriptase polymerase chain reaction (RT-PCR) amplified a product corresponding to amino acid positions 30 to 278 of the $V$. inaequalis cytochrome $b(31,44)$. This region contained all amino acids reported to be involved in target-site resistance to QoIs $(5,6,21)$. RT-PCR products were prepared for all isolates and sequenced in both directions with an ABI automated DNA sequencer with fluorescent-dye-labeled didoxy terminators, utilizing the pair of PCR primers.

Data analysis. Sequence comparisons were done using the Lasergene software (DNASTAR, Inc., Madison, WI). The analysis of in vitro sensitivities followed procedures employed previously $(24,25$, 29,30). Mean sensitivities of RGm, RGg, and $\mathrm{ED}_{50}$ values of populations or isolates were compared by $t$ test analysis. Categorical data (ratios of sensitive and resistant isolates and distributions of isolate sensitivities) were compared by log-linear analysis. Disease incidence data were transformed using arcsin transformation, and the transformed data were analyzed using ANOVA. Treatment means were separated using Fisher's protected LSD test.

\section{RESULTS}

Characterization of a $V$. inaequalis population from a commercial orchard in Michigan. Sensitivities to kresoximmethyl. An apple orchard in Michigan had received eight QoI treatments over the course of two seasons when unsatisfactory control of scab was noticed. In order to compare the kresoxim-methyl sensitivity of V. inaequalis isolates retrieved from this site with the kresoxim-methyl baseline sensitivities determined previously $(29,30)$, relative germination of clonal conidia was tested with kresoxim-methyl at $0.01 \mu \mathrm{g} \mathrm{ml}^{-1}$ and with kresoxim-methyl plus SHAM at $0.1 \mu \mathrm{g} \mathrm{ml}^{-1}$.

Sensitivity tests conducted at the dose of kresoxim-methyl at $0.01 \mu \mathrm{g} \mathrm{ml}^{-1}$ revealed a shift of the Michigan orchard population toward quantitatively declining kresoximmethyl sensitivities (Fig. 1). In baseline populations, $4.8 \%$ of $V$. inaequalis isolates displayed RGg values $>90$ (29). This portion had increased 13-fold at the Michigan orchard (Fig. 1). Moreover, the mean RGg value of the Michigan isolates had increased from a baseline value of 68 (29) to a value of 90 . The differences between mean RGg values and frequency distributions (Fig. 1) were highly significant $(P<$ 0.001), demonstrating a strong quantitative response of the $V$. inaequalis population toward declining kresoxim-methyl sensitivities.

Tests at a dose of kresoxim-methyl plus SHAM 10-fold higher (at $0.1 \mu \mathrm{g} \mathrm{ml} \mathrm{m}^{-1}$ ) confirmed the significant shift of isolate sensitivities. Conidia of $33 \%$ of the 52 isolates tested continued to germinate (Table 1) compared with full inhibition achieved for all 250 baseline isolates tested

Table 1. Distribution of isolate sensitivities in tests with kresoxim-methyl plus salicylhydroxamic acid at $0.1 \mu \mathrm{g} \mathrm{ml} \mathrm{g}^{-1}$

\begin{tabular}{lcc}
\hline & \multicolumn{2}{c}{ Frequency of isolates (\%) } \\
\cline { 2 - 3 } Inhibition of conidia germination $(\boldsymbol{\%})^{\mathbf{x}}$ & Baseline $^{\mathbf{y}}$ & Michigan $^{\mathbf{z}}$ \\
\hline$>95$ & 100 & 67.3 \\
$95-80$ & 0 & 25.0 \\
$79-70$ & 0 & 5.8 \\
$69-70$ & 0 & 1.9 \\
$<70$ & 0 & 0 \\
$n$ & 250 & 52 \\
\hline
\end{tabular}

${ }^{\mathrm{x}}$ Percentages of inhibition of conidia germination are expressed as 100 minus relative germination.

y Data are from Olaya and Köller 1999 (30).

${ }^{\mathrm{z}}$ Isolates were collected at an orchard in Michigan in 2001. 
previously (30). This departure from the baseline frequency distribution was highly significant $(P<0.001)$. However, the inhibition of conidia germination was $\geq 70 \%$ for all isolates tested (Table 1). In contrast, conidia germination was not affected for a laboratory G143A target site mutant of $V$. inaequalis when tested at a 30-fold higher kresoxim-methyl dose plus SHAM (45), suggesting that target site mutants or other highly resistant yet SHAM-insensitive isolates (35) were not detected in the Michigan orchard population. The results indicated a quantitative rather than a qualitative response of the $V$. inaequalis population (Fig. 1), with highly resistant phenotypes remaining below a detectable frequency.

Comparison of target site sequences. The lack of sequence alterations in the cytochrome $b$ target site was confirmed by sequence analyses. RT-PCR products of cytochrome $b$ spanning the entire QoI binding region $(21,44)$ were sequenced for five isolates retrieved from the Michigan orchard. Three isolates typified the subpopulation selected at the site, with $\mathrm{RGg}$ values of 100 displayed at a kresoximmethyl dose of $0.01 \mu \mathrm{g} \mathrm{ml}{ }^{-1}$ (Fig. 1) and continued germination observed at $0.1 \mu \mathrm{g}$ $\mathrm{ml}^{-1}$ plus SHAM (Table 1). Two isolates represented typical baseline isolates (Fig. 1).

Nucleotide sequences were identical for all five isolates (data not shown). They contained the glycine in position 143 typical for QoI-sensitive isolates of $V$. inaequalis, and the deduced amino acid sequences did not depart from any of the sequences described previously for other baseline isolates of the pathogen $(31,35,44,45)$.

Sensitivities to the DMI fenarimol. Scab management programs at the Michigan orchard had relied, for over 10 years, on DMIs mixed with a conventional protectant following the recommendations of a delayed DMI spray program (39). This previous DMI history of the orchard prompted us to test the level of DMI resistance established at the site. Isolate sensitivities to fenarimol demonstrated that the $V$. inaequalis population at the Michigan orchard was fully DMI resistant (Table 2), with a resistance level not significantly different $(P=0.73)$ from the threshold of practical fenarimol resistance (24).

Table 2. Fenarimol sensitivity of a Venturia inaequalis population retrieved from an orchard in Michigan

\begin{tabular}{lccc}
\hline & \multicolumn{3}{c}{ Frequency of isolates $(\%)$} \\
\cline { 2 - 4 } RGm $^{\mathbf{y}}$ & Baseline $^{\mathbf{z}}$ & Resistance threshold & Michigan orchard \\
\hline $0-80(\mathrm{~S})$ & 98.3 & 58.7 & 57.7 \\
$>81(\mathrm{R})$ & 1.7 & 41.3 & 42.3 \\
$n$ & 748 & 104 & 52 \\
\hline y & Relative growth of mycelial colonies with fenarimol at $0.05 \mu \mathrm{g} \mathrm{ml}^{-1} . \mathrm{R}$ and $\mathrm{S}$ in parenthesis desig- \\
nate sensitive and resistant isolates, respectively. & \\
${ }^{\mathrm{z}}$ Isolate frequencies typical for populations never treated with fenarimol (baseline) or for populations \\
responding with practical resistance to fenarimol (resistance threshold) are from Köller et al. 1997 \\
(23).
\end{tabular}

previously for baseline isolates (30). In similar tests employing mixtures of conidia derived from an undefined number of diseased leaves, the baseline $\mathrm{ED}_{50}$ value for trifloxystrobin was $0.0035 \mu \mathrm{g} \mathrm{ml} \mathrm{m}^{-1}$ (26). This value departed considerably from the value of $0.054 \mu \mathrm{g} \mathrm{ml}^{-1}$ measured for the 16 baseline isolates described in this study. In summary, the comparison of the two QoIs, kresoxim-methyl and trifloxystrobin, indicate similar inhibitory potencies under the in vitro test conditions employed in this study.

Modification of the QoI sensitivity test. The procedure of testing conidia prepared from mycelia of individual isolates $(29,31)$ is laborious. Moreover, the QoI sensitivities measured for the stage of conidia germination do not reflect the subsequent inhibition of mycelial colony formation, a measure with potential relevance in afterinfection applications of QoIs. In order to simplify the sensitivity test and to include the initial stage of mycelial growth, the test procedure was modified. Sensitivities of conidia derived from distinct scab lesions producing clonal conidia were tested directly, and the development of mycelia was included in the test by measuring colony growth after 7 days of development. Moreover, the discriminatory QoI test doses were doubled in order to allow for improved quantification of initial population responses, as advised by the magnitude of the initial population response documented for the Michigan orchard (Fig. 1).

The modified test procedure necessitated the establishment of new baseline data for both QoIs. This goal was accomplished by testing conidia derived from infected leaves sampled from nonmanaged backyard trees remote from commercial apple orchards. At the discriminatory doses of $0.02 \mu \mathrm{g} \mathrm{ml}^{-1}$ employed for both QoIs (Fig. 3), mean RGm values for the baseline population were 11 for kresoxim-methyl and 13 for trifloxystrobin, and were not significantly different $(P=0.76)$. The results confirmed the nearly equivalent in-

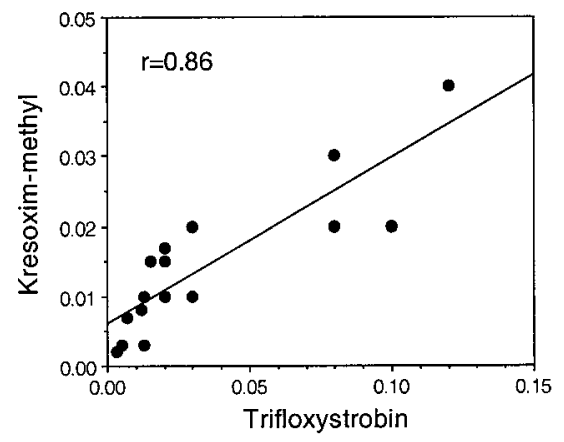

Fig. 2. Correlation of $\mathrm{ED}_{50}$ values $(50 \%$ effective dose) of kresoxim-methyl and trifloxystrobin determined for 16 isolates in the presence of salicylhydroxamic acid at $100 \mu \mathrm{g} \mathrm{ml}^{-1}$. QoI (fungicides acting as respiration inhibitors by binding to the Qo center of cytochrome $b$ ) concentrations are given in $\mu \mathrm{g} \mathrm{ml}^{-1}$. 
hibitory potencies of the two QoIs described above for the stage of conidia germination.

QoI and DMI sensitivities at an experimental orchard in New York. The performance of QoI fungicides in the management of scab has been evaluated at the experimental orchard since 1994. Comparison with baseline sensitivities revealed that the population of $V$. inaequalis had responded with a quantitative shift toward declining QoI sensitivities (Fig. 3). For kresoximmethyl, the mean RGm value was increased to 44 from a baseline value of 26 $(P<0.001)$. This increased mean sensitivity was accompanied by a significant $(P<$ $0.001)$ change of isolate sensitivity distributions for kresoxim-methyl (Fig. 3A). The same pattern was obtained for trifloxystrobin. The mean RG values increased from 24 to $34(P<0.001)$, and the sensitivity distribution had shifted significantly $(P$ $<0.001)$ from the baseline distribution toward decreasing sensitivity to trifloxystrobin (Fig. 3B).

In order to identify isolates expressing a high level of QoI resistance reminiscent of the laboratory target site mutant described previously (44), sensitivities also were tested at 10-fold higher kresoxim-methyl and trifloxystrobin doses in mixture with

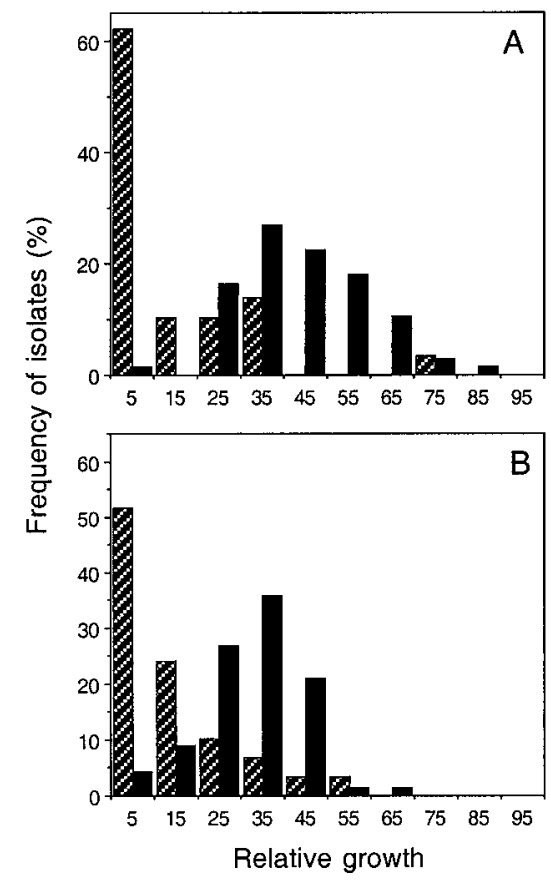

Fig. 3. Frequency distributions of Venturia inaequalis isolate sensitivities to fungicides acting as respiration inhibitors by binding to the Qo center of cytochrome $b$ (QoIs). Sensitivities of mycelial colonies formed after 7 days from germinating conidia were tested with $\mathbf{A}$, kresoxim-methyl and $\mathbf{B}$, trifloxystrobin at 0.02 $\mu \mathrm{g} \mathrm{ml} \mathrm{l}^{-1}$. Hatched bars designate the distribution of baseline isolates retrieved from nonmanaged apple trees in Pennsylvania $(n=29)$. Closed bars reflect the sensitivity distribution determined for isolates obtained from an experimental orchard in New York $(n=67)$.
SHAM. The formation of mycelial colonies from germinating conidia was prevented completely for all isolates tested (data not shown), indicating that highly resistant target site mutants remained below a detectable level.

Sensitivity tests conducted in 1998, 1999, and 2000 demonstrated that the experimental orchard had become fully resistant to DMIs after 16 years of DMI testing (W. Köller and W. F. Wilcox, unpublished remyclobutanil resistance significantly exceeding $(P=0.004)$ the threshold of practical resistance (Table 3). Very similar to the results obtained for the Michigan orchard described above (Fig. 1 and Table 2), isolate sensitivities to the DMI myclobutanil and the two QoIs were largely independent traits. Although mean QoI sensitivities were numerically larger for the DMI-resistant subpopulation, the differences were statistically not significant (Table 4).

Performance of myclobutanil and QoI fungicides. The experimental orchard site described above was diagnosed as fully DMI resistant (Table 3), and a significant population shift toward decreased QoI sensitivities in response to 8 years of QoI testing was evident (Fig. 3). The impact of these two consecutive population responses on the performance of QoI fungicides was investigated in 2002 (Table 5).

The scab management program reflected a rotation of the conventional protectant mancozeb with respective fungicide treatments. Mancozeb applied alone over the entire season provided significant control of fruit scab at the time of harvest (Table 5 ). The alternation of mancozeb with a myclobutanil-mancozeb mixture had no additional effect on the incidence of fruit scab, confirming the status of practical sults). Tests in 2002 confirmed a level of

DMI resistance (Table 3). However, control of fruit scab was improved significantly when mancozeb was rotated with the QoIs kresoxim-methyl or trifloxystrobin applied at two different application rates, which reflected current recommendations and grower practice in the United States (Table 5). The results demonstrated that both QoIs provided effective control of fruit scab, in spite of full DMI resistance established at the site (Table 3) and a significant shift of the pathogen population toward declining QoI sensitivities (Fig. 3).

Including myclobutanil in mixture with mancozeb in the rotation program improved the control of leaf scab above the level achieved with mancozeb alone (Table 5). Replacing the DMI-mancozeb mixture with QoIs provided additional improvement of leaf scab control, although the levels of control were lower than for fruit scab (Table 5). Very similar results on both fruit and leaf scab control have been reported for trials conducted in 2000 at the same experimental orchard (38).

Characterization of a $V$. inaequalis population from a commercial orchard in Germany. In 2001, a mixture of conidia derived from an apple orchard in North Germany indicated a high level of kresoxim-methyl resistance. Scab developed freely on leaves of apple seedlings inoculated with the conidia and treated with kresoxim-methyl at $500 \mu \mathrm{g} \mathrm{m} \mathrm{m}^{-1}$, compared with $>95 \%$ control achieved at 4 $\mu \mathrm{g} \mathrm{ml}^{-1}$ with conidia for 25 baseline populations (29). In the monitoring of $V$. inaequalis population sensitivities to kresoxim-methyl conducted from 1997 to 2000, gradual shifts toward decreasing QoI sensitivities had been observed, but development of scab was fully prevented on

Table 3. Myclobutanil sensitivity of a Venturia inaequalis population retrieved from an experimental orchard in New York

\begin{tabular}{lccc}
\hline & \multicolumn{3}{c}{ Frequency of isolates (\%) } \\
\cline { 2 - 4 } $\mathbf{R G m}^{\mathbf{y}}$ & Baseline $^{\mathbf{z}}$ & Resistance threshold $^{\mathbf{z}}$ & Experimental orchard \\
\hline $0-80(\mathrm{~S})$ & 97.8 & 56.7 & 34.3 \\
$>81(\mathrm{R})$ & 2.2 & 43.3 & 65.7 \\
$n$ & 627 & 104 & 67 \\
\hline
\end{tabular}

${ }^{\mathrm{y}}$ Relative growth of mycelial colonies with fenarimol at $0.05 \mu \mathrm{g} \mathrm{ml}^{-1}$. R and $\mathrm{S}$ in parenthesis designate sensitive and resistant isolates, respectively.

${ }^{\mathrm{z}}$ Isolate frequencies typical for populations never treated with myclobutanil (baseline) or for populations responding with practical resistance to myclobutanil (resistance threshold) are from Köller et al. 1997 (23).

Table 4. Fungicides acting as respiration inhibitors by binding to the Qo center of cytochrome $b$ (QoI) sensitivities of the demethylation-inhibiting fungicide (DMI)-sensitive and -resistant subpopulations of a Venturia inaequalis population of an experimental orchard in New York

\begin{tabular}{lcccccc}
\hline & & \multicolumn{2}{c}{ Kresoxim-methyl } & & \multicolumn{2}{c}{ Trifloxystrobin } \\
\cline { 3 - 4 } \cline { 6 - 7 } Population & $\boldsymbol{n}$ & Mean RGm & $\boldsymbol{P}^{\mathbf{z}}$ & & Mean RGm $^{\mathbf{y}}$ & $\boldsymbol{P}^{\mathbf{z}}$ \\
\hline DMI-sensitive & 23 & 40.2 & $\ldots$ & & 30.0 & $\ldots$ \\
DMI-resistant & 44 & 45.3 & 0.19 & & 36.0 & 0.13 \\
\hline
\end{tabular}

${ }^{\mathrm{y}}$ Mean relative growth of mycelial colonies determined at QoI doses of $0.02 \mu \mathrm{g} \mathrm{ml}{ }^{-1}$.

${ }^{z}$ Probability levels $(t$ test) for comparisons of mean RG-values for DMI-sensitive (RG $\leq 80)$ and DMI-resistant $(\mathrm{RG}>80)$ subpopulations. 
leaves treated with the fungicide at $500 \mu \mathrm{g}$ $\mathrm{ml}^{-1}$ (K. Cronshaw, unpublished results).

Because the highly resistant 2001 population of $V$. inaequalis conidia was derived from 40 diseased leaves, isolates were prepared from single conidia after the mixture of conidia had completed three disease cycles on nontreated leaves of apple seedlings. Sequencing of the cytochrome $b$ specific RT-PCR product derived from the combined mycelia of eight isolates identified the same G143A mutation of cytochrome $b$ reported for the highly resistant laboratory mutant described previously (45). Guanine involved in encoding a glycine in position 143 (45) was not detected (data not shown), indicating that the mutated mitochondrial cytochrome $b$ allele had been selected to an apparent homoplasmic state.

The dose response of conidia prepared from mycelium of one of the G143A-target site mutants was determined for both kresoxim-methyl and trifloxystrobin in the presence of SHAM. Although conidia germination of a typical baseline isolate displayed $\mathrm{ED}_{50}$ values for both kresoximmethyl and trifloxystrobin at approximately $0.01 \mu \mathrm{g} \mathrm{ml}^{-1}$, conidia germination of a target site mutant was not inhibited at $10 \mu \mathrm{g} \mathrm{ml}^{-1}$ (Fig. 4). The result demonstrated a resistance factor of $>1,000$ for both QoIs and confirmed that respective target site mutants were not detected at the Michigan orchard described above (Fig. 1 and Table 1). A high level of QoI resistance also was apparent under the conditions of our new test procedure, where colony development was not affected at a dose of trifloxystrobin plus SHAM at $0.2 \mu \mathrm{g} \mathrm{ml}^{-1}$ (Fig. 5). Similarly resistant isolates were not detected in the experimental orchard in New York. Instead, initial population shifts toward declining QoI sensitivities were quantitative (Fig. 3).

\section{DISCUSSION}

The response of $V$. inaequalis populations to QoI fungicides described in this study constitutes a fourth round of resistance development for this pathogen. Both quantitative and qualitative resistance responses have been described. Resistance to dodine and the DMIs developed as quantitative sensitivity shifts $(24,25)$, whereas resistance to the benzimidazoles such as benomyl was typical for a qualitative response $(17,18)$. For the DMIs, it was shown that resistant subpopulations continued to respond to high doses of the fungicides (22). In the benomyl case, resistance was caused by mutational changes of the $\beta$-tubulin target site conferring benzimidazole immunity to mutant isolates $(14,15)$.

The question of whether resistance to the new class of QoI fungicides would proceed as a quantitative or qualitative population response had not been resolved at the time of their commercial introduction. Respective risk analyses were complicated by two factors. It was shown that alternative respiration as a mechanism of escape from QoI action was expressed in vitro but not when host leaves were protected prior to infection $(3,21,29,31,46)$. Moreover, the cytochrome $b$ gene encoding the QoI target site is encoded by multiallelic mitochondrial DNA $(21,43,45)$. Consequently, a mutational cytochrome $b$ target site change in a single mitochondrium would first require its selection within an affected isolate before a resistant phenotype would emerge.

Our QoI risk assessment studies involving both baseline and mutation studies predicted the risk of quantitative but also the potential for qualitative resistance $(21,29-31,44,45)$. The results presented in this study largely confirmed these predictions. Here, we documented that the development of QoI resistance of $V$. inaequalis can progress through a quantitative path or through the selection of immune G143A target site mutants giving rise to qualitative resistance. Both scenarios were predicted from the results of our risk-assessment studies $(21,29-31,45)$. A similar scenario of both quantitative and qualitative paths of resistance development has not been described for any previous class of fungicides $(7,16,19)$. Although not documented in this study, the two paths of resistance development might occur consecutively, with quantitative population responses succeeded by the selection of highly resistant G143A mutants $(21,45)$.

A two-phase development of QoI resistance for $V$. inaequalis populations would have impact on the design of anti-resistance strategies. Although the quantitative QoI sensitivity shift described here for our experimental orchard did not diminish QoI performances in a largely protective scab management program, the initial shift at the commercial Michigan orchard was accompanied by unsatisfactory control of scab. This comparison provides circumstantial evidence that initial shifts toward declining QoI sensitivities can compromise the level of disease control under certain management conditions, but that management changes such as the rotation of QoIs

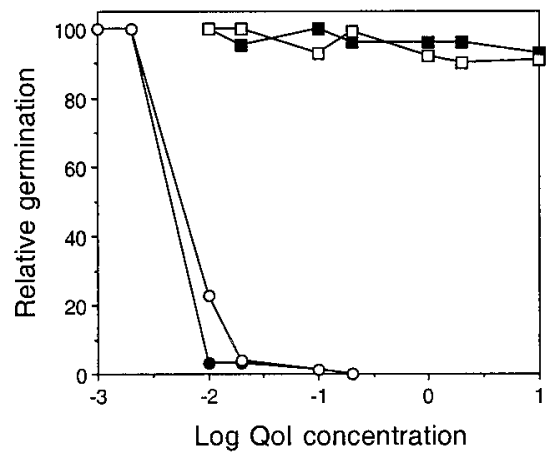

Fig. 4. Dose responses of germinating conidia prepared from a typical baseline isolate (circles) and from a G143A target site mutant originating from an orchard in Germany (squares) to the fungicides acting as respiration inhibitors by binding to the Qo center of cytochrome $b$ (QoIs) kresoxim-methyl (closed symbols) and trifloxystrobin (open symbols). Tests were performed in the presence of salicylhydroxamic acid. Log QoI concentrations are given in $\mu \mathrm{g} \mathrm{ml}^{-1}$.

Table 5. Fungicide performance in the management of apple scab in 2002 at an experimental orchard in New York

\begin{tabular}{|c|c|c|c|c|c|}
\hline \multirow[b]{2}{*}{ Fungicidew $^{w}$} & \multirow[b]{2}{*}{ Rate (g a.i./ha) $)^{x}$} & \multicolumn{2}{|c|}{ Fruit scab } & \multicolumn{2}{|c|}{ Leaf scab } \\
\hline & & Incidence $^{y}$ & Control $(\%)^{\mathrm{z}}$ & Incidencey $^{y}$ & Control $(\%)^{\mathrm{z}}$ \\
\hline Untreated check & & $92.9 \mathrm{a}$ & $\ldots$ & $78.5 \mathrm{a}$ & $\ldots$ \\
\hline Mancozeb & 2,500 & $17.7 \mathrm{~b}$ & 81 & $42.7 \mathrm{~b}$ & 46 \\
\hline Myclobutanil + mancozeb & $126+2,500$ & $21.8 \mathrm{~b}$ & 77 & $26.7 \mathrm{c}$ & 66 \\
\hline Kresoxim-methyl & 140 & $3.7 \mathrm{c}$ & 96 & $18.5 \mathrm{c}$ & 76 \\
\hline Kresoxim-methyl & 221 & $2.0 \mathrm{c}$ & 97 & $16.5 \mathrm{c}$ & 79 \\
\hline Trifloxystrobin & 70 & $5.0 \mathrm{c}$ & 95 & $15.2 \mathrm{c}$ & 81 \\
\hline Trifloxystrobin & 105 & $3.7 \mathrm{c}$ & 96 & $16.0 \mathrm{c}$ & 80 \\
\hline
\end{tabular}

${ }^{w}$ Mancozeb at a rate of 2,500 g a.i./ha was applied to all treated blocks on 18 April (tight cluster), 1 May (extended pink), and 15 May (late bloom-early petal fall). The test fungicides were applied on 24 April (pink), 8 May (bloom), 21 May (petal fall), and 29 May (first cover). The fungicide program was completed with five applications of thiophanate-methyl (180g a.i./ha) in mixture with captan (1,700 g a.i./ha) to all treated blocks on 13 and $26 \mathrm{June}$, 11 and 25 July, and 7 August.

$x$ Application rates were based on a spray volume of 2,800 liters/ha.

${ }^{y}$ Incidences of fruit scab were determined on 16 August by recording the presence of at least one scab lesion for 100 fruit per tree. Incidences of leaf scab were determined for 10 leaves on 10 terminal branches per tree. Means within columns not followed by a common letter are significantly different from each other according to Fisher's protected least significant difference $(P<0.05)$.

z Percentages of control were calculated as 100 - incidence (treated)/incidence (nontreated). 
with unrelated fungicides are likely to restore satisfactory levels of scab control. Similar management changes are unlikely to mitigate QoI immunity expressed by G143A target site mutants.

Relevant questions are whether the initially quantitative sensitivity shifts can be slowed down, and whether this tactic also would delay the emergence and selection of highly resistant target site mutants. For the DMI fungicides with their quantitative pattern of resistance development, it was shown that sensitivity shifts can be slowed and managed with high fungicide doses (22). For the QoIs, a high dose will be defined not only by the application rate but also by the timing of applications. In contrast to the DMIs with their pronounced after-infection activities (20,36,39), QoIs generally are most active in a protective rather than an after-infection mode of applications $(1,3,6,12,40,43)$. Therefore, it can be expected that QoIs applied after infection will allow isolates with sensitivities lower than average to develop lesions, thereby accelerating their speed of selection.

The question of whether a slower development of quantitative resistance will also slow the speed of subsequent qualitative population responses remains largely unknown. It has been demonstrated, however, that the selection of stable target site mutants is preceded by the selection of single mutated mitochondria within a distinct phenotype. For Plasmopora viticola, it was found that a mutated cytochrome $b$ allele frequency of $2 \%$ was sufficient to confer phenotypic expression of QoI resistance

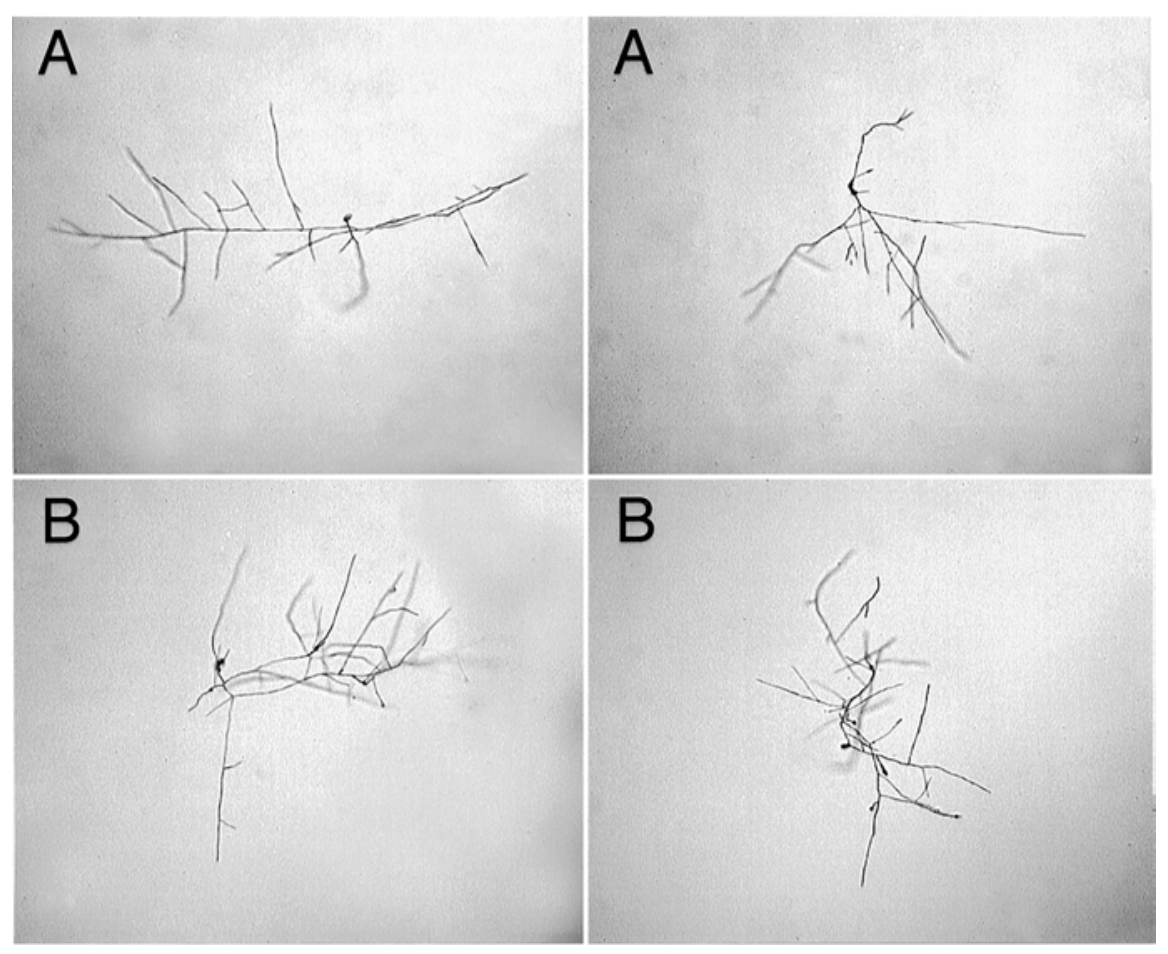

Fig. 5. Mycelial colonies developing from a G143A target site mutant originating from an orchard in Germany after 7 days of incubation. Potato dextrose agar was amended with $\mathbf{A}$, salicylhydroxamic acid at $100 \mu \mathrm{g} \mathrm{ml}{ }^{-1}$ or $\mathbf{B}$, a mixture of salicylhydroxamic acid with trifloxystrobin at $0.2 \mu \mathrm{g} \mathrm{ml}^{-1}$.

(34). For Blumeria graminis f. sp. tritici (acronym: Erysiphe graminis f. sp. tritici) it was demonstrated that some QoIresistant isolates containing a heteroplasmic cytochrome $b$ allele population slowly returned to a QoI-sensitive stage when they were relieved from selection pressure (9). A dynamic fluctuation of cytochrome $b$ alleles also was reported for a laboratory mutant of $V$. inaequalis (45).

Circumstantial evidence for Magnaporthe grisea infecting barley leaves suggested that the selection or even generation of single mutated QoI-resistant mitochondria is fostered by allowing continued growth of fungal cells $(2,4)$, and that such conditions are provided in afterinfection applications of QoIs (1). Continued growth accelerating the speed of mitochondria selection is suppressed in protective applications of QoIs, where the expression of alternative respiration is largely silenced $(2,3,31,42,46)$. Therefore, emphasis on protective applications of QoIs might be expected to slow the speed of both the quantitative and qualitative population responses of $V$. inaequalis.

The apple orchards in Michigan and New York described in this study also were fully resistant to DMIs, in addition to their quantitative shifts toward declining QoI sensitivities. It has been suggested for powdery mildew of grapevine that isolate sensitivities to DMIs and QoIs are not entirely independent traits (41), similar to the interdependence of isolate sensitivities to DMI and dodine reported for $V$. inaequalis (23). Thus, the frequency of isolates prone to quantitative selection by a
QoI could be increased in DMI-resistant populations. With the sample size of isolates investigated, however, significant interdependence of isolate sensitivities to QoIs and DMIs was not apparent for $V$. inaequalis. This lack of significant interdependence was supported by the observation that both QoIs provided effective control of apple scab when tested at our fully DMI-resistant experimental orchard.

In summary, the data described in this study demonstrate that resistance of $V$. inaequalis to the class of QoI fungicides might have progressed in the two phases of quantitative and qualitative response of $V$. inaequalis populations. Thus far, only circumstantial evidence exists to suggest that slowing the speed of quantitative sensitivity shifts might also slow the speed of subsequent qualitative resistance. Our new in vitro test procedure described was designed to detect both types of $V$. inaequalis population responses to the QoI fungicides, allowing the site-specific and responsive management of QoI resistance.

\section{ACKNOWLEDGMENTS}

We thank F. Chow, Bayer CropScience, for collecting diseased apple leaves in Pennsylvania and H. B. Davey, UAP Great Lakes, for providing leaves from Michigan.

\section{LITERATURE CITED}

1. Avila-Adame, C., and Köller, W. 2002. Disruption of the alternative oxidase gene in Magnaporthe grisea and its impact on host infection. Mol. Plant-Microbe Interact. 15:493500.

2. Avila-Adame, C., and Köller, W. 2002. Interrelation between alternative respiration and target site mutations in response to QoI fungicides. Pages 829-834 in: Proc. Brighton Conf. Pests Dis. 2002. British Crop Protection Council, Farnham, UK.

3. Avila-Adame, C., and Köller, W. 2003. Impact of alternative respiration and target-site mutations on responses of germinating conidia of Magnaporthe grisea to Qo-inhibiting fungicides. Pest Manag. Sci. 59:303-309.

4. Avila-Adame, C., and Köller, W. 2003. Characterization of spontaneous mutants of Magnaporthe grisea expressing stable resistance to the Qo inhibiting fungicide azoxystrobin. Curr. Genet. 42:332-338.

5. Avila-Adame, C., Olaya, G., and Köller, W. 2003. Characterization of Colletotrichum graminicola isolates resistant to strobilurinrelated QoI fungicides. Plant Dis. 87:14261432.

6. Bartlett, D. W., Clough, J. M., Godwin, J. R., Hall, A. A., Hamer, M., and Parr-Dobranzki, B. 2002. The strobilurin fungicides. Pest Manag. Sci. 58:649-662.

7. Brent, K. J. 1995. Fungicide Resistance in Crop Pathogens: How Can It be Managed? FRAC Monograph No. 1, GIFAP, Brussels.

8. Colson, A.-M. 1993. Random mutant generation and its utility in uncovering structural and functional features of cytochrome $b$ in $S a c$ charomyces cerevisiae. J. Bioenerg. Biomembr. 25:211-220.

9. Fraaije, B. A., Butters, J. A., Coelho, J. M., Jones, D. R., and Hollomon, D. W. 2002. Following the dynamics of strobilurin resistance in Blumeria graminis f. sp. tritici using quantitative allele-specific real-time PCR measurements with the fluorescent dye SYBR Green I. Plant Pathol. 51:45-54.

10. Gisi, U., Sierotzki, H., Cook, A., and McCaf- 
fery, A. 2002. Mechanisms influencing the evolution of resistance to Qo inhibitor fungicides. Pest. Manag. Sci. 58:859-867.

11. Heaney, S. P., Hall, A. A., Davies, S. A., and Olaya, G. 2000. Resistance to fungicides in the QoI-STAR cross-resistance group: Current perspectives. Pages 755-762 in: Proc. Brighton Conf. Pests Dis. 2000. British Crop Protection Council, Farnham, UK.

12. Hoffman, L. E., and Wilcox, W. F. 2003. Factors influencing the efficacy of myclobutanil and azoxystrobin for control of grape black rot. Plant Dis. 87:273-281.

13. Joseph-Horne, T., Hollomon, D. W., and Wood, P. M. 2001. Fungal respiration: a fusion of standard and alternative components. Biochim. Biophys. Acta 1504:179-195.

14. Koenraadt, H., and Jones, A. L. 1992. The use of allele-specific oligonucleotides probes to characterize resistance to benomyl in field strains of $V$. inaequalis. Phytopathology 82:1354-1358

15. Koenraadt, H., Somerville, S. C., and Jones, A. L. 1992. Characterization of mutations in the beta-tubulin gene of benomyl-resistant field strains of Venturia inaequalis and other plant pathogenic fungi. Phytopathology 82:13481354.

16. Köller, W. 1991. Fungicide resistance in plant pathogens. Pages 679-720 in: CRC Handbook of Pest Management in Agriculture, 2nd ed., vol. 2. D. Pimentel, ed. CRC-Press, Boca Raton, FL.

17. Köller, W. 1995. Managing resistance to sterol demethylation inhibitors. Pages 340-349 in: Eighth Int. Congr. Pestic. Chem. Options 2000. N. N. Ragsdale, P. C. Kearny, and J. R. Plimmer, eds. American Chemical Society, Washington, DC

18. Köller, W. 1996. Recent developments in DMI resistance. Pages 301-311 in: Modern Antifungal Compounds. H. Lyr, P. E. Russel, and H. D. Sisler, eds., Intercept Ltd., Andover, UK.

19. Köller, W. 2001. Fungicide resistance. Pages 483-488 in: Encyclopedia of Plant Pathology. O. C. Maloy, and T. D. Murray, eds. John Wiley, New York.

20. Köller, W. 2003. Fungicides, sterol biosynthesis inhibitors. Pages 628-640 in: Encyclopedia of Agrochemicals. J. R. Plimmer, ed. John Wiley, New York.

21. Köller, W., Avila-Adame, C., Olaya, G., and Zheng, D. 2001. Resistance to strobilurin fungicides. Pages 215-229 in: Agrochemical Resistance: Extent, Mechanism, and Detection. J.
M. Clark and I. Yamaguchi, eds. American Chemical Society, Washington, DC.

22. Köller, W., and Wilcox, W. F. 1999. Evaluation of tactics for managing resistance of Venturia inaequalis to sterol demethylation inhibitors. Plant Dis. 83:857-863.

23. Köller, W., and Wilcox, W. F. 2000. Interactive effects of dodine and the DMI fungicide fenarimol in the control of apple scab. Plant Dis. 84:863-870.

24. Köller, W., Wilcox, W. F., Barnard, J., Jones, A. L., and Braun, P. G. 1997. Detection and quantification of resistance of Venturia inaequalis populations to sterol demethylation inhibitors. Phytopathology 87:184-190.

25. Köller, W., Wilcox, W. F., and Jones, A. L. 1999. Quantification, persistence and status of dodine resistance in New York and Michigan orchard populations of Venturia inaequalis. Plant Dis. 83:66-70.

26. Küng Färber, R. B., Chin, K. M., and Leadbitter, N. 2002. Sensitivity of V. inaequalis to trifloxystrobin. Pest Manag. Sci. 58:261-267.

27. Kunz, S., Lutz, B., Deising, H., and Mendgen, K. 1998. Assessment of sensitivities to anilinopyrimidine- and strobilurin-fungicides in populations of the apple scab fungus Venturia inaequalis. J. Phytopathol. 146:231-238.

28. Leung, H., Nelson, R. J., and Leach, J. E. 1993. Population structure of plant pathogenic fungi and bacteria. Adv. Plant Pathol. 10:157-205.

29. Olaya, G., and Köller, W. 1999. Baseline sensitivities of Venturia inaequalis populations to the strobilurin fungicide kresoxim-methyl. Plant Dis. 83:274-278.

30. Olaya, G., and Köller, W. 1999. Diversity of kresoxim-methyl sensitivities in baseline populations of Venturia inaequalis. Pestic Sci. 55:1083-1088.

31. Olaya, G., Zheng, D., and Köller, W. 1998. Differential response of germinating Venturia inaequalis conidia to kresoxim-methyl. Pestic. Sci. 54:230-236.

32. Parker, D. M., Hilber, U. W., Bodmer, M., Smith, F. D., Yao, C., and Köller, W. 1995. Production and transformation of conidia of Venturia inaequalis. Phytopathology 85:87-91.

33. Sauter, H., Steglich, W., and Anke, T. 1999. Strobilurins: Evolution of a new class of active substances. Angew. Chem. Int. Ed. 38:13281349.

34. Sirven, C., Gonzales, E., Bufflier, E., Latorse, M. P., and Beffa, R. 2002. PCR-based method for detecting mutation allele frequencies for QoI resistance in Plasmopora viticola. Pages
823-828 in: Proc. Brighton Conf. Pests Dis. 2002. British Crop Protection Council, Farnham, UK.

35. Steinfeld, U., Sierotzki, H., Parisi, S., Poirey, S., and Gisi, U. 2001. Sensitivity of mitochondrial respiration to different inhibitors in Venturia inaequalis. Pest Manag. Sci. 57:787-796.

36. Szkolnik, M. 1981. Physical modes of action of sterol-inhibiting fungicides against apple diseases. Plant Dis. 65:981-985.

37. Von Jagow, G. V., and Link, T. A. 1986. Use of specific inhibitors on the mitochondrial $b c_{1}$ complex. Methods Enzymol. 126:253-271.

38. Wilcox, W. F., Burr, J. A., and Heidenreich, G. 2000. Evaluation of fungicide programs for control of apple scab and powdery mildew of apples, 2000. Fungic. Nematicide Tests 57:PF37.

39. Wilcox, W. F., Wasson, D. I., and Kovach, J. 1992. Development and evaluation of an integrated reduced-spray program using sterol demethylation inhibitor fungicides for control of primary apple scab. Plant Dis. 76:669-677.

40. Wong, F. P., and Wilcox, W. F. 2001. Comparative physical modes of action of azoxystrobin, mancozeb, and metalaxyl against Plasmopora viticola (grapevine downy mildew). Plant Dis. 85:649-656.

41. Wong, F. P., and Wilcox, W. F. 2002. Sensitivity to azoxystrobin among isolates of $\mathrm{Un}$ cinular necator: Baseline distribution and relationship to myclobutanil sensitivity. Plant Dis. 86:649-656

42. Wood, P. M., and Hollomon, D. W. 2003. A critical evaluation of the role of alternative oxidase in the performance of strobilurin and related fungicides acting at the Qo site of complex III. Pest Manag. Sci. 59:499-511.

43. Ypema, H. L., and Gold, R. E. 1999 Kresoxim-methyl. Modification of a natura occurring compound to produce a new fungicide. Plant Dis. 83:4-19.

44. Zheng, D., and Köller, W. 1997. Characterization of the mitochondrial cytochrome $b$ gene from Venturia inaequalis. Curr. Genet. 32:361366.

45. Zheng, D., Olaya, G., and Köller, W. 2000 Characterization of laboratory mutants of Venturia inaequalis resistant to the strobilurinrelated fungicide kresoxim-methyl. Curr Genet. 38:148-155

46. Ziogas, B. N., Baldwin, B. C., and Young, J. E. 1996. Alternative respiration: a biochemica mechanism of resistance to azoxystrobin (IC 5504) in Septoria tritici. Pestic. Sci. 50:28-40. 